\title{
BIOGRAFÍAS ILUSTRADAS Y CONSTRUCCIÓN DEL CANON AUTORIAL (ENTRE ESPAÑA Y EUROPA): DE PACHECO A SEDANO*
}

Pedro Ruiz Pérez

(Universidad de Córdoba)

pruiz@uco.es

RESUMEN: En torno a dos obras españolas destacadas, el Libro de retratos (1599-1644) de Pacheco y el Parnaso español (1768-1778) de López de Sedano, se plantea la consideración genérica de la hibridación de biografías y retratos con una muestra textual antológica, los antecedentes de su aplicación a los escritores, su dimensión europea y su función en los procesos de institucionalización de la literatura y de construcción de la subjetividad autorial.

PALABRAS ClAVE: Biografías ilustradas, Francisco Pacheco, Juan José López de Sedano, Libro de retratos, Parnaso español, canon, imagen de autor.

\section{ILLUSTRATED BIOGRAPHIES AND CONSTRUCTION OF THE AUTHORIAL CANON (BETWEEN SPAIN AND EUROPE): FROM PACHECO TO SEDANO}

ABSTRACT: Around two outstanding Spanish works, the Libro de retratos (15991644) by Pacheco and the Parnaso español (1768-1778) by López de Sedano, I study the generic consideration of the hybridisation of biographies and portraits with an anthology of texts, the antecedents of their application to writers, their European dimension and their role in the processes of institutionalisation of literature and the construction of author subjectivity.

KEYWORDS: Illustrated biographies, Francisco Pacheco, Juan José López de Sedano, Libro de retratos, Parnaso español, canon, author fashioning.

Cerca de su ecuador, el siglo XIX consolida el modelo de historias literarias nacionales, a impulsos, entre otros factores, de la ideología burguesa y su proyección en la deriva de la estética romántica (Romero Tobar, 2008). En Alemania aparecen en la década de los 40 las obras de Heinrich Geizer (1841), Friedrich Rinne (1842-1843), Joseph Hillebrand (1845-1846) o Georg Gottfried Gervinus (1849). La literatura británica cuenta con el panorama enciclopédico de Robert Chambers (1843-1844), y en España el Manual de literatura de Gil y Zárate (1842-1844) se compone y publica en estrecha relación con la reforma educativa que el propio autor impulsa desde su cargo ministerial, hasta la plasmación de la Ley de Instrucción Pública (1855-1857), que incluye la materia en el curriculum escolar y, por tanto, en el imaginario ideológico de

* El artículo recoge resultados de los trabajos enmarcados en el proyecto Sujeto e institución literaria en la edad moderna (FFI2014-54367-C2-1-R del Plan Estatal de I+D+i) y los desarrolla como parte del plan de trabajo del proyecto que lo continúa, Biografías y polémicas: hacia la institucionalización de la literatura y el autor (SILEM II), RTI2018-095664-B-C21. Una versión previa se presentó en el Convegno Internazionale Forme e modi dell'autorialità nella cultura europea dalla prima età moderna alla contemporaneità (Firenze, 25-26 de octubre de 2018). Para el volumen resultante se encuentra en prensa una versión adaptada y en inglés de estas páginas. 
las sucesivas generaciones. También queda fijada con este proceso una noción de canon en la que se normaliza la propia concepción de la literatura y, en lo que nos toca, la imagen y representación de sus autores. Con anterioridad, antologías, colecciones de biografías y galerías de retratos son componentes activos en esa construcción, y actúan con particular efecto cuando se entrelazan, resaltando las interrelaciones entre ellas y entre canon e imagen de autor.

Mi propósito es acercarme a esas modalidades incipientes de representación autorial en la edad moderna, con particular atención a distintas realizaciones de un género de formas híbridas, que, junto a textos poéticos, combina retratos pintados y semblanzas escritas. Lo hacen en distinta proporción y con estrategias diferenciadas, pero comparten, en lo que he llamado «biografías ilustradas», la presentación de figuras individualizadas y la forma seriada de hacerlo, estableciendo a la vez la subjetividad autorial y la institucionalización de su perfil colectivo. En ellas confluyen, por tanto, las dos grandes líneas estratégicas de self-fashioning (Greenblatt, 1980), la de la afirmación individual y la de la defensa de la poesía, esto es, la de una práctica aún en debate en los siglos XVI y XVII, con los discursos de Du Bellay, Tasso y Sidney (Ferguson, 1983), ya antes del conocido texto de Shelley.

Trabajos previos (García Aguilar y Sáez, 2016; Montero y Sánchez Jiménez, 2017; Lorenzo Álvarez, 2017; Aradra y Esteve, 2017; Ruiz Pérez, 2018a; Özmen y Padilla Aguilera, 2019; y Ruiz Pérez, 2019 y en prensa a) permiten la formulación de unas ideas que sirven de premisas y marco conceptual para las observaciones que siguen. De manera sintética, son las siguientes:

1) La construcción del canon colectivo está ligada a la conformación de una imagen de autor y al modo en que se concreta su función (Foucault, 1969). Entre los siglos XVI y XVII el progresivo asentamiento de la función autorial en el texto y su correspondiente responsabilidad, fijada en la creciente regulación legislativa, van destacando las figuras de referencia, en una dialéctica de interactuación con un conjunto donde los contemporáneos aproximan su peso al de los antiqui auctores. En otras palabras, los escritores de estos siglos proyectan su autoridad (desde la auctoritas de los clásicos a un moderno sentido de la autoría) ${ }^{1}$ para avalar la dignidad del conjunto, en tanto la existencia de este actúa como espacio necesario para la emergencia de la subjetividad autorial.

2) La lista, nómina o serie (Eco, 2009) implica la determinación de requisitos para integrarla, antes de establecer una jerarquía en su seno. Impulsadas inicialmente por los propios autores (Ruiz Pérez, 2010), las galerías de nombres de escritores, trasladadas de modelos establecidos para reyes, héroes o santos, evidencian una continuidad para lo que es presentado y percibido como conjunto. Este sujeto colectivo es definido por elementos de consonancia, pero también de diferencia respecto a otras series cronológicas o geográficas, asumiendo respecto a ellas una identidad susceptible de ser ordenada, entre la secuencia y la jerarquía.

${ }^{1}$ La heterogeneidad del proceso se acentúa con los géneros: en el teatro se relaciona con el éxito comercial; en la prosa se sigue gestionando en torno a la veracidad factual o moral; y en la poesía, con una mayor proyección del yo y la persistencia de un modo de difusión restringido, tienen una incidencia más directa las estrategias de autorrepresentación (Ruiz Pérez, 2009). 
3) La inclusión de los escritores y su distribución en el campo literario (Bourdieu, 1995) requieren previamente el establecimiento como tal de este orden sociocultural; y, aunque el autor del concepto sitúa su plena realización en la Francia de mediados del siglo XIX, su forja comienza mucho antes, impulsada por la mentalidad preburguesa, el ámbito humanista y el desarrollo de la imprenta. En sus etapas iniciales sobre todo, las estrategias individuales conviven y se funden en muchos casos con un discurso de afirmación general, introduciendo respecto a la noción clásica de «parnaso» el principio de temporalidad, en una inicial dialéctica de antiguos y modernos, paralela a la de identidad geográfica y cultural.

4) La estrategia de las series corresponde a la afirmación de un grupo diferenciado, estético o ideológico, local o nacional, con manifestaciones nítidas en el ámbito hispánico (García Aguilar, 2006; Álvarez Amo, 2008 y 2010). Los vínculos con la antigüedad clásica y aun los paralelos con otros modelos de la tradición europea sirven inicialmente para la consecución del reconocimiento, pero pronto habrán de ser superados para dibujar una república literaria de ámbito más reducido y de definición más precisa, como se manifiesta en otros entornos socioculturales, como la Francia del Grand Siècle (Viala, 1985).

5) Las antologías (como las de la poesía pospetrarquista estudiada por Manero Sorolla, 1983, para el caso español), las biografías a imitación de las de los autores clásicos (Dubel, 2001; Davis y Burdiel, 2005; Boillet et al., 2012; Residori et al., 2014; Pask, 1996; Bradford, 2018) y una imagen plástica de creciente individualidad (Ferrari, 2005; Piper, 1982) actúan como elementos determinantes en el proceso, y multiplican sus efectos cuando se presentan de manera combinada, en una eficaz articulación. Es la plasmación de este modelo la que centrará las páginas que siguen.

\section{DISPOSITIO «EDITORIAL» Y CONCEPTO EN DOS REFERENTES HISPÁNICOS}

Con sus significativas diferencias, pero también con unos elementos comunes en su composición, los siglos XVII y XVIII en España quedan enmarcados por dos obras de referencia en el género que hemos identificado para nuestro estudio. La primera es el códice del pintor y agente cultural sevillano Francisco Pacheco, Libro de descripción de verdaderos retratos de ilustres y memorables varones, por Francisco Pacheco (15991644), manuscrito de dilatada composición (Cacho Casal, 2011), conservado hoy en su núcleo principal en la Fundación Lázaro Galdiano de Madrid (Pacheco, 1985). La segunda se despliega en 9 volúmenes realizados en los talleres de los dos impresores más importantes del momento, Joaquín Ibarra y Antonio de Sancha, entre 1768 y 1778, en forma de antología titulada Parnaso español. Colección de poesías escogidas de los más célebres poetas castellanos, firmada por Juan José López de Sedano. La cronología que abarcan supone un período de casi dos siglos, que incluye el de una reconocida fase de culminación de las letras hispanas (el siglo de Cervantes, Góngora y Lope) y el de inventario, ordenación y definición conceptual (con la bibliografía de Nicolás Antonio y las actividades de la Real Academia Española).

Aunque el autor pudiera haberlo concebido en algún momento para la publicación (Bassegoda i Hugas, 1990; Cacho Casal, 2011), el primero es un manuscrito 
de carácter académico, en el sentido propio de una academia humanista, como agrupación no formalizada de ingenios, con un núcleo definido y localizado (también en el tiempo), que entrelaza sus actividades con una cierta conciencia de identidad colectiva. La colaboración en la empresa de Pacheco es una muestra de esa conciencia compartida, manifestada en la disposición a posar para el retratista o en la aportación de textos para el conjunto.

Francisco Pacheco, Libro de retratos (1599-1644),

Ms. Fundación Lázaro Galdiano (ed. cit.).

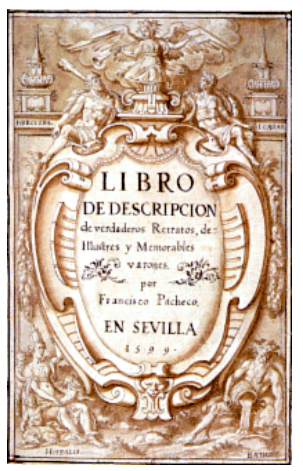

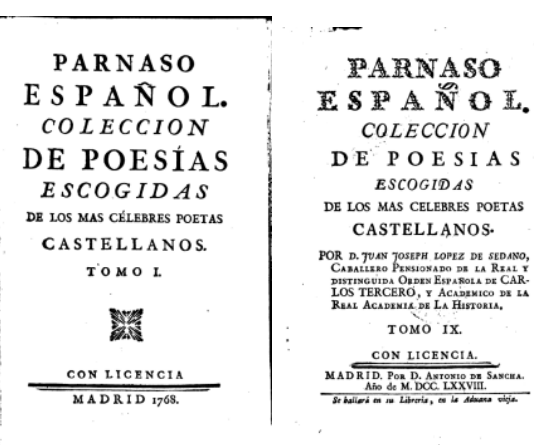

Juan José López de Sedano, Parnaso español, Madrid, Joaquín Ibarra-Antonio de Sancha, 1768-1778. ${ }^{2}$

El Parnaso, por el contrario, es una colección impresa de gran amplitud cronológica en su selección, desde finales del siglo XV hasta el momento de su composición, con dos principios de unidad: el género de la poesía y una afirmada concepción nacional ligada a la lengua castellana. Aunque pudo contar en un primer momento con alguna colaboración, muy pronto abandonada, ${ }^{3}$ la de Sedano es una empresa individual, que se inscribe, eso sí, en una extendida práctica filológica de las décadas ilustradas y su voluntad de re-construcción del pasado, en una búsqueda interrelacionada de tradición nacional y modelos estéticos.

Las dos incluyen retratos, biografías y poemas, pero lo hacen en proporción diferente, con distinto orden y distinto valor. Más que si se tratara de modelos idénticos, las divergencias ponen de manifiesto y destacan la esencia de una modalidad discursiva compartida, en su capacidad de adaptarse a propósitos y circunstancias cambiantes.

En el Libro de Pacheco los elementos de la composición se articulan a partir del núcleo del retrato, ${ }^{4}$ resaltado en el título y propio de la condición profesional del suegro de Velázquez, autor asimismo de un Arte de la pintura (1649, póstumo). En este caso podríamos decir que la semblanza ilustra (en doble sentido) la imagen plástica, con una

$2<$ https://bivaldi.gva.es/es/consulta/registro.cmd?id $=4551>$ y

$<$ https://bivaldi.gva.es/es/consulta/registro.cmd?id=4580>. Como todas las demás reproducciones digitales, la última consulta data del 19 de junio de 2019.

${ }^{3}$ Sigue en disputa el grado de colaboración de Vicente de los Ríos desde la polémica de Sedano con Iriarte (Ruiz Pérez, en prensa b).

4 Véase McDonald (2007), para extender sus consideraciones acerca del significado de la práctica de este personaje francés del siglo XVI como coleccionista de retratos y autor de varias compilaciones de semblanzas. 
narratio que tiene más de prosopopeya que de prosopografía, pues predomina la voluntad de definir los rasgos mayores de una personalidad sobre la de establecer el relato de una vida o la enumeración cronológica de unas obras, que, por otra parte, en muchos casos de los letrados incluidos, no llegaron a plasmarse como tales, apelando más bien su alabanza a conocimientos académicos y ejercicios de convivialidad culta. A las semblanzas se añaden composiciones laudatorias en verso, en muchos casos con carácter de epitafio, ya que Pacheco esperaba a la muerte del personaje para cerrar su representación en el códice in fieri. Por esta razón no todos los «retratos» individuales están completos, con pinturas inacabadas y ausencias de algunos de los componentes adicionales, sobre todo en las páginas del final, cuando el fallecimiento del compilador se adelanta al de los retratados en ciernes.

De manera sistemática, el retrato consta del busto del personaje, su nombre en una cartela y un marco arquitectónico. En los rostros predomina el empeño, repetidamente explicitado por Pacheco, de dotarlos de veracidad en la representación, con atención a sus rasgos individualizados y la adición prácticamente sistemática de elementos externos de caracterización, como hábitos religiosos, cruces caballerescas u otras vestimentas denotadoras de la condición social. Los marcos arquitectónicos varían de un retrato a otro, dentro de un carácter común de ornamentación orientada a la dignificación del contenido, de modo que la transición estética al cultismo barroco se pone al servicio de esta voluntad pragmática. Como se ha indicado, los retratos de las páginas finales carecen en algún caso de este elemento, e incluso del nombre del personaje, como indicio de un trabajo incompleto por la circunstancia señalada. Se aprecia por ello que se trata de una especie de work in progress, que Pacheco fue desarrollando durante más de 40 años, hasta su muerte, en una persistencia en la que cabe reconocer una voluntad más definida que la que podría revelar una circunstancial finalización con destino a la imprenta.

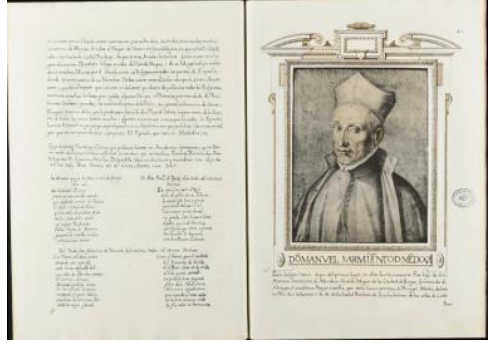

Pacheco, ed. cit.
El final de las páginas dedicadas a fray Agustín Núñez Delgadillo y el comienzo de las que abre el retrato de don Manuel Sarmiento de Mendoza recogen el conjunto de componentes en la representación de cada figura, con el final de la semblanza textual y los poemas dedicados, de un lado, y el retrato enmarcado, de otro.
El retrato y la semblanza de don Manuel Sarmiento de Mendoza quedan sin el complemento de los poemas, mientras que en el apartado siguiente, dedicado a fray Miguel de Santiago, queda incluso sin completar el retrato, carente de marco y de cartela para la indicación del nombre

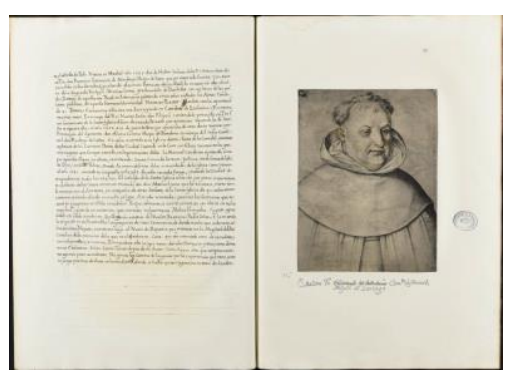

Pacheco, ed. cit. 
A lo largo de cuatro décadas de trabajo sistemático, lo que permanece constante es el concepto de la obra, que combina la singularización del retrato y la regularidad de la serie. Esta condición se percibe en las semblanzas y demás textos que las acompañan, pero también en los propios retratos, incluyendo el papel que juega en el segundo vector (la serie) el marco arquitectónico (infra), que integra los rostros singulares en un conjunto identificable, con el desplazamiento que lleva desde una dignificación propia de las figuras aristocráticas a la canonización de la práctica letrada.

El designio de la obra es la afirmación (entre el reconocimiento reivindicativo y el encomio celebrativo) de un grupo selecto e identitario, nucleado en el entorno sevillano y en una tradición «académica» que arranca con Juan de Mal Lara a mediados del siglo XVI y se prolonga, en gran medida por la actividad de Pacheco (Montero, 2016; Montero y Cacho Casal, 2014), a lo largo del siglo XVII, para florecer de nuevo en la segunda mitad del siglo XVIII, en una especie de reencarnación de la «escuela sevillana» (López Bueno, 1989 y 1992).

En la obra de Sedano, caracterizada por su formato editorial y los parámetros de las prácticas ilustradas, el punto focal es diferente, desplazándose la centralidad a los textos poéticos, aunque manteniendo los retratos y las biografías una importante función connotativa, también dirigida a la canonización, tanto de la serie como de sus figuras más relevantes. De hecho, inicialmente, se trata de una antología, como se anuncia en la portada de los volúmenes con las referencias de «parnaso» y «colección» recogidas en el título; en el primer volumen, tras la introducción editorial, el lector solo encuentra la selección de poemas. En cambio, desde el volumen II (Joaquín de Ibarra, 1770) preceden a los poemas la «Noticia de los poetas castellanos que componen el Parnaso Español», recogiendo las biografías omitidas en el primer tomo en el que le sigue. También empiezan a incluirse los retratos de algunos de los autores (no faltando los de mayor relieve, por una u otra causa); sin embargo, mientras las vidas se agrupan al inicio, en una serie que destaca paralelismos identificables como propios de una identidad colectiva, los retratos aparecen salpicados entre los textos, posiblemente por razones de amenidad que se imponen a las de la economía de la producción impresa.
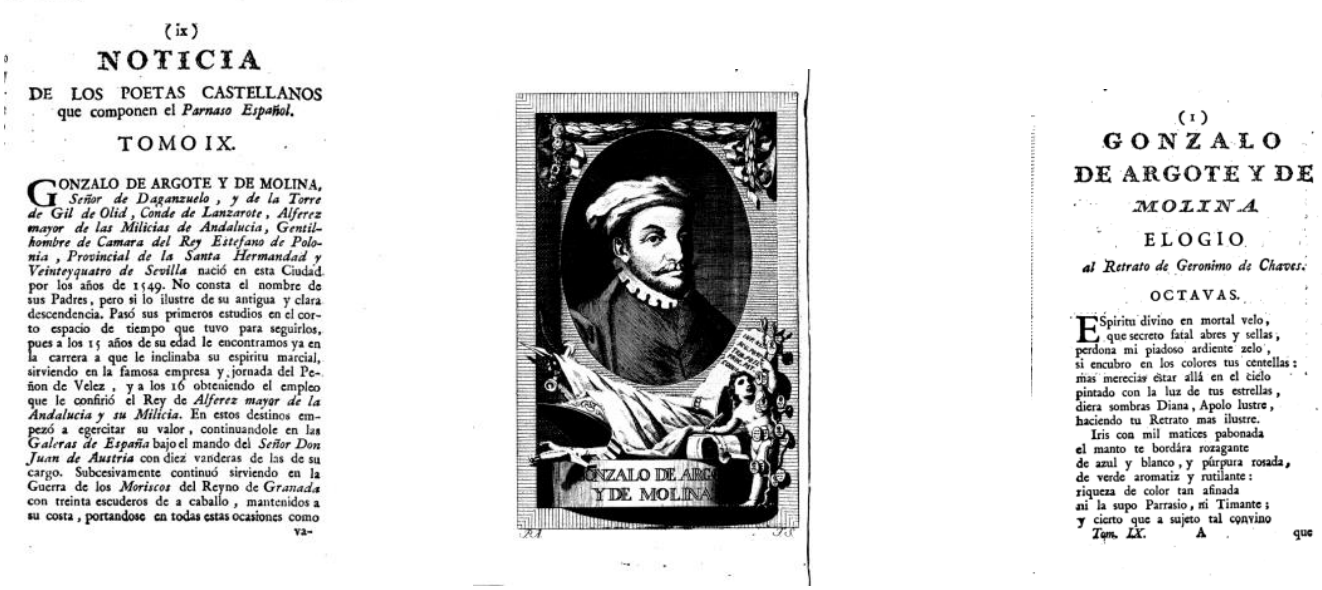

Juan José López de Sedano, Parnaso español, tomo IX, Madrid, Antonio de Sancha, $1778 .{ }^{5}$

5 〈https://bivaldi.gva.es/es/consulta/registro.cmd?id=4580>. 
El conjunto resultante repite los mismos componentes manejados por Pacheco (noticia, retrato y poemas), pero en un orden alterado fruto de la distancia en la concepción (propia de un ya consolidado género antológico) y la correspondiente economía compositiva. La diferencia en el orden de los elementos manifiesta una diferencia de intención, sentido y efectos. Así, en Pacheco encontramos un orden que podemos calificar de descendente, por la disminución de la importancia de los elementos siguientes a partir del retrato, para concluir en los epitafios; la estructura se convierte en circular en la reiteración de una figura a otra; los «verdaderos retratos» se manifiestan como la viga maestra de todo el edificio del códice.

En la antología de Sedano el orden se invierte y se hace ascendente, hasta llegar a los poemas seleccionados de cada autor, que rematan los elementos previos, en forma de generalizada semblanza del autor y retratos escogidos; el conjunto textual se ofrece bien segmentado y ordenado, con un aparato previo a los textos propio de la explanatio textuum o accesus ad auctores del comentario humanista. Su designio aparece apuntado en la doble redundancia apreciable en la portada: el valor colectivo propio de «parnaso» (como agrupación de poetas) se hace explícito en «colección», mientras que el adjetivo «español» del primer término se desdobla, a modo de sinónimo insistente, en la caracterización de «castellanos» que se destaca en los poetas celebrados y elevados a la corte de Apolo.

En ambos discursos y en los volúmenes que los plasman, a más de 150 años de distancia en lo que toca a su génesis, la diferencia fundamental, junto a la de la ordenación, estriba en las dimensiones del corpus de poemas incluidos. Por el contrario, la sistematicidad interna y el paralelismo entre las dos obras comienza por la regularidad retórica de las semblanzas (Ruiz Pérez, en prensa c); en segundo lugar, tiene en los retratos (infra) un elemento sustancial de normalización, al establecer con los lectores (de las obras respectivas y de la producción de los escritores) una presencia casi física, que otorga entidad al autor y proyecta su auctoritas en sus propios textos. Una mirada a algunos modelos y obras cercanas ilustra la pertinencia de estas compilaciones, que, por razones de espacio y ocasión, consideraremos centrándonos en la ilustración de las biografías.

\section{MODELOS CABALLERESCOS Y HAGIOGRÁFICOS}

Ya en el mundo clásico, a las series de semblanzas de príncipes y héroes se unieron las de los filósofos, con las reconocidas y extendidas series de Herodoto, Plutarco y Diógenes Laercio (Ruiz Pérez, 2018b), sin que aparecieran vidas como tales en series consagradas a los hombres de letras. En el medievo hispánico, la hegemonía de oratores y bellatores no se tradujo en galerías de semblanzas, al margen de la difusión de la «leyenda áurea» de Jacobo de la Vorágine y otros textos asociados a su modelo. En el prehumanismo caballeresco del siglo XV, en cambio, aparecen textos como las Generaciones y semblanzas (1450-1455; ed. 1512), de Pérez de Guzmán, y los Claros varones de España (1486), de Hernando del Pulgar, aunque la presencia de escritores en sus páginas es muy limitada, por no decir nula, ya que, como ocurre con la semblanza 
del marqués de Santillana, hasta se omite esta faceta en el caso de producirse. Como cabía esperar por el pobre desarrollo de la imprenta y el mercado del libro, pero también por la escasa consideración de la identidad individual de los personajes, en los impresos no se incluyen retratos de los biografiados, como si su representación dependiese más bien de una imagen de casta o linaje, el de la aristocracia caballeresca. En cambio, en taco xilográfico tomado de otras obras, la portada ofrece una representación autorial, la del compilator de la galería, como oferente ante la reina-mecenas, en una clara aplicación de un principio de exaltación monárquica y nacional al que se subordina toda noción autorial, pareja a la ausencia de biografías de escritores y de representaciones plásticas individualizadas.

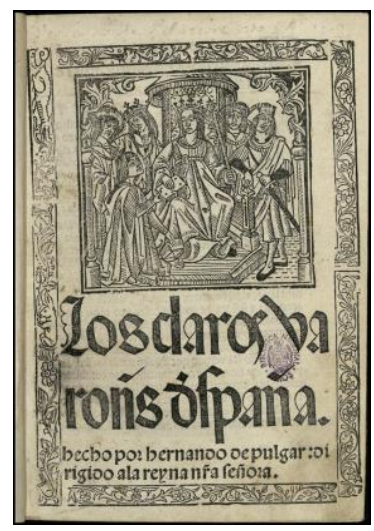

Sevilla, por Estanislao Polono, $1500 .^{6}$

En el siglo de la Contrarreforma, el retorno de los santos impulsa la colección de sus biografías de forma reiterada, hasta desembocar en las colecciones más importantes, el Flos sanctorum de Alonso de Villegas (5 volúmenes entre 1578 y 1598, con numerosas reediciones), y el del jesuita Pedro de Rivadeneyra (con dos entregas entre 1599 y 1601), este último autor también de una extensa biografía (o hagiografía) de Ignacio de Loyola, fundador de la Compañía de Jesús. En el primer caso sí encontramos imágenes entre las páginas del impreso, como si el habitual recurso para amenizar la lectura se orientara también a una posible vinculación entre la imagen física y la de la santidad del personaje. Sin embargo, observamos un fenómeno paralelo al de la codificación de la portada de Hernando del Pulgar, que, más que la ausencia, aleja la singularidad del autor. Las ilustraciones del texto de Villegas muestran, con la reiteración del uso del mismo taco xilográfico para diferentes santos, que no se persigue una vera effigies, sino exclusivamente la amenidad para los lectores (delectare) y la fijación de unos valores a través de una iconografía alegórica (prodesse) en la que se plasman gestos esenciales de una imagen ideal de la santidad.

\footnotetext{
$6<$ http://www.bibliotecavirtualdeandalucia.es/catalogo/es/consulta/registro.cmd?id=1001892>.
} 
Alonso de Villegas, Flos Sanctorum y historia general de la vida y hechos de Jesucristo, Toledo, viuda de Juan de Rodríguez, 1591. ${ }^{7}$

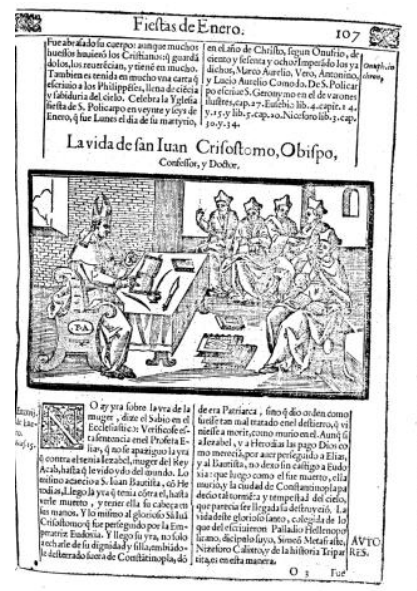

f. 107 r.

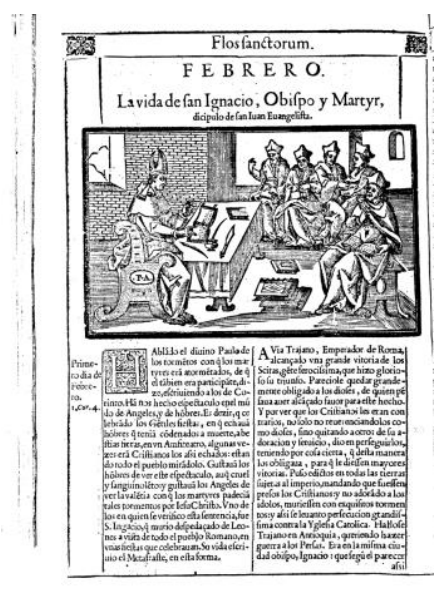

f. 111v.

En el ejemplo repetido para la vida de Juan Crisóstomo y la del obispo Ignacio es el carácter magistral de un modelo teologal, en que el estudio representado en la mesa de trabajo con los útiles de escritura complementa la iluminación divina. Curiosamente, lo que la imagen tiene de representación autorial, coincidente en gran medida con una iconografía habitual del escritor en su gabinete o scriptorium (Buiguès, en prensa), introduce una neutralización, al sumar a la falta de rasgos individuales y su carácter intercambiable, de uno a otro personaje, la ausencia de marcas de diferenciación entre el autor religioso y cualquier otra modalidad, ocultando cualquier distinción del creador literario. No obstante, también cabe la lectura inversa, pues, al aparecer una imagen similar en los preliminares de una obra profana, su autor se hace partícipe, aunque sea en forma indirecta, de la auctoritas reconocida a padres y jerarcas de la iglesia. Estamos aún lejos de la galería de retratos individuales; sin embargo, el modelo editorial del Flos sanctorum tiende un puente hacia formas como las que estamos considerando.

La extensión del modelo y su constitución como una referencia que puede ser usada para otros grupos se refleja también en una compilación singular, los Elogios de mujeres insignes del Viejo Testamento, de Martín Carrillo, aún en el espacio de la celebración religiosa.

${ }^{7}<$ https://books.google.es/books/about/Flos_sanctorum_y_historia_general_de_la.html?id=FB5H yoeju9sC\&redir_esc $=y>$. 

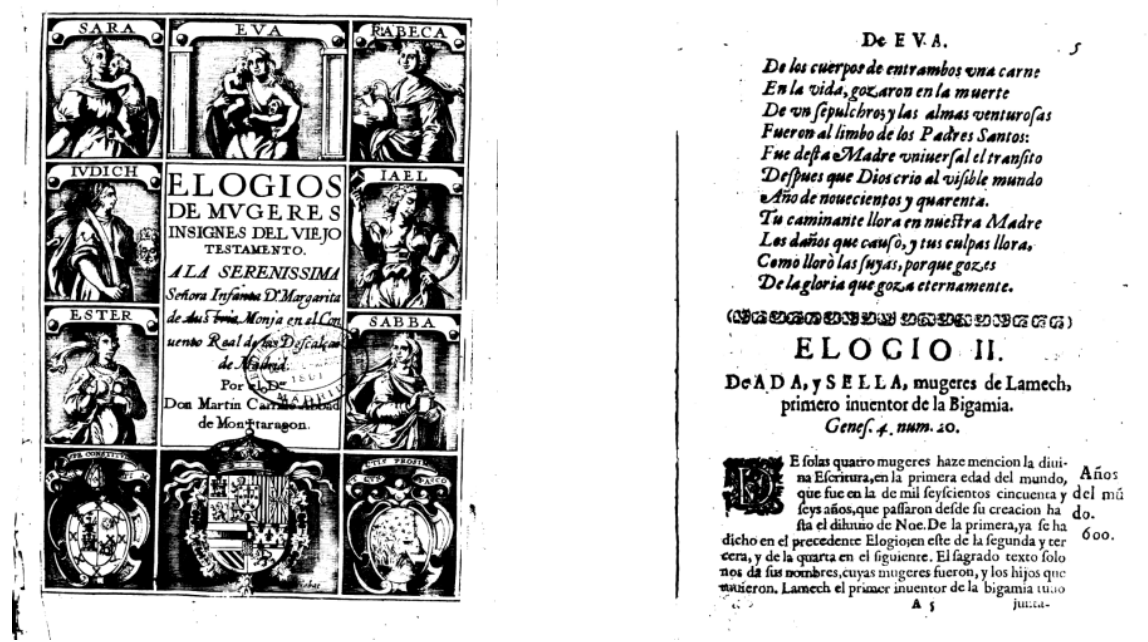

Martin Carrillo, Elogios de mujeres insignes del Viejo Testamento, en Huesca, por Pedro Blusón, 1627.8

Su singularidad radica en la condición femenina de sus personajes y su origen veterotestamentario; su modelo, sin embargo, coincide con el del entonces aún manuscrito Libro de Pacheco, incluyendo retratos, elogios en prosa y poemas celebrativos, reforzando la inserción de la empresa sevillana en un discurso reconocible, antes de su extensión a los hombres de letras.

En el volumen de Carrillo destacan dos peculiaridades. De un lado, reconocemos la voluntad de individualización de los retratos, no en la fisonomía personal y la veracidad del rostro, sino en la incorporación de motivos iconográficos de valor alegórico; es el caso de la maternidad de Sara y Eva, la espada de Judit y la cabeza de Holofernes, la majestad y magnanimidad de Ester... Por otra parte, resulta significativa la concentración de los retratos en la portada, acentuando la imagen de comunidad, junto a la de profusión, lo que traslada al lector la importancia del grupo objeto de la obra. Nos encontramos ya ante un modelo fijado para el horizonte español, que se imbrica con otros referentes europeos para consolidar la fórmula y su aplicación al campo literario.

\section{REALIZACIONES EUROPEAS}

La existencia desde mediados del siglo XVI de muestras del género de «biografías ilustradas» en distintos países traza un panorama continental de progresivo asentamiento de esta forma de representación privilegiada de la república letrada o artística.

Las similitudes en la composición de la portada con el volumen anterior pueden justificar el inicio de este breve repaso por la obra de William Winstanley, England's Worthiest select lives of most eminent persons, cuya primera edición data de 1660, antes de reaparecer en 1684 con todo su componente de ilustraciones.

${ }^{8}<$ https://books.google.es/books/ucm?vid=UCM5320773427\&printsec=frontcover\&redir_esc $=y$ $\# \mathrm{v}=$ onepage \&q\&f=false> . 


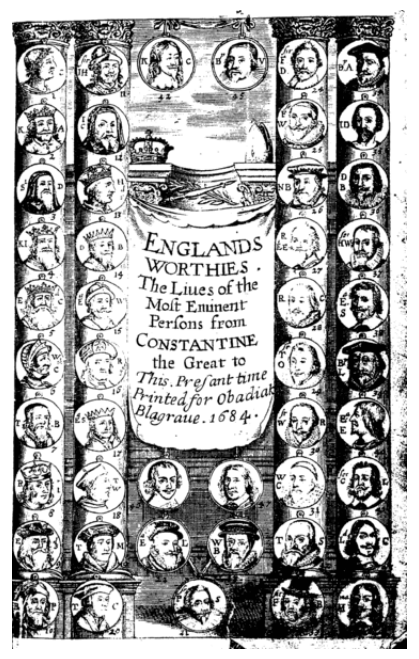

William Winstanley, England's Worthiest select lives of most eminent persons, $1684 .^{9}$

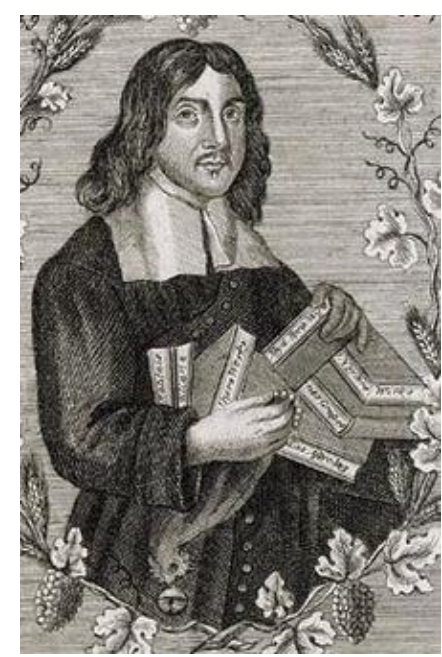

William Winstanley, The Loyall Martyrology, $1667 .{ }^{10}$

Lo relativamente tardío de su fecha apunta hacia la continuidad y proyección de un modelo y su plena asunción para el campo de la república de las letras, con una deliberada ambigüedad. De una parte, en el título los viri illustres son sustituidos por «persons», pero ni una sola mujer se incluye en el índice ni aparece en una portada que reproduce el patrón seguido por Carrillo. Por otra parte, en el subtítulo interior la materia se concreta en The lives of the most famous English poets, from William the Conqueror, to these present times (subrayado mío), como si ya los hombres de letras hubieran patrimonializado la condición de los miembros más eminentes del reino, bendecidos además por la fama. Desde la portada ilustrada, la profusa galería de retratos pone de manifiesto la entidad de una república letrada en la que alternan reyes, prelados y burgueses.

El sentido de la obra se hace más manifiesto atendiendo al retrato del autor. No se incluye en este volumen, sino que lo encontramos en un martirologio confeccionado por Winstanley con aires de actualidad. La materia responde a los conflictos religiosos de la Inglaterra del siglo XVII, en paralelo al pacto entre monarquía y nobleza que proponía Hernando del Pulgar. Doscientos años después, lo que ha cambiado es la representación autorial: en lugar de arrodillado ante el príncipe-mecenas, Winstanley aparece ahora erguido y exento, además de adornado con significativos atributos: el hábito clerical, los libros y la orla de vid y trigo. Lo que se resalta es un valor de utilidad e, indirectamente, el horizonte nacional a que se aplica, en cuya construcción desempeña un papel de gran importancia la cultura impresa y los autores que la mantienen.

Volviendo al ámbito de las letras en la colección de biografías y elogios recogidos en la obra, nos interesa destacar dos aspectos. Como vemos en la reedición de 1684 , los retratos se concentran en portada, reafirmando la idea de cantidad y apuntando un parnaso, que se confirma con la inclusión de 147 autores en el índice de personajes, en un modo diferente de los planteados anteriormente en España por el Viaje del

\footnotetext{
$9<$ https://en.wikipedia.org/wiki/William_Winstanley $>$.

$10<$ https://en.wikipedia.org/wiki/William_Winstanley $>$.
} 
parnaso (1614) de Cervantes y el Laurel de Apolo (1630) de Lope de Vega. Coincidiendo sobre todo con este último, la idea de la fama, en el subtítulo, ordena la república de los poetas y establece un principio de canonización, desarrollado en biografías (parcial y esquemáticamente) ilustradas.

Retrocediendo a la fuente moderna y laica de este tipo de colecciones, hemos de llegar a Giorgio Vasari y su colección verdaderamente inaugural, Le vite de piu eccellenti pittori, scultori e achitettori, aparecida por primera vez en 1550 y objeto de numerosas reediciones, en una extensión que revela el gran reconocimiento que la obra tuvo y la relevancia que se le otorgó.

El acceso a su tratamiento de la imagen lo encontramos en tres rasgos de bibliografía material de la edición florentina de 1568.
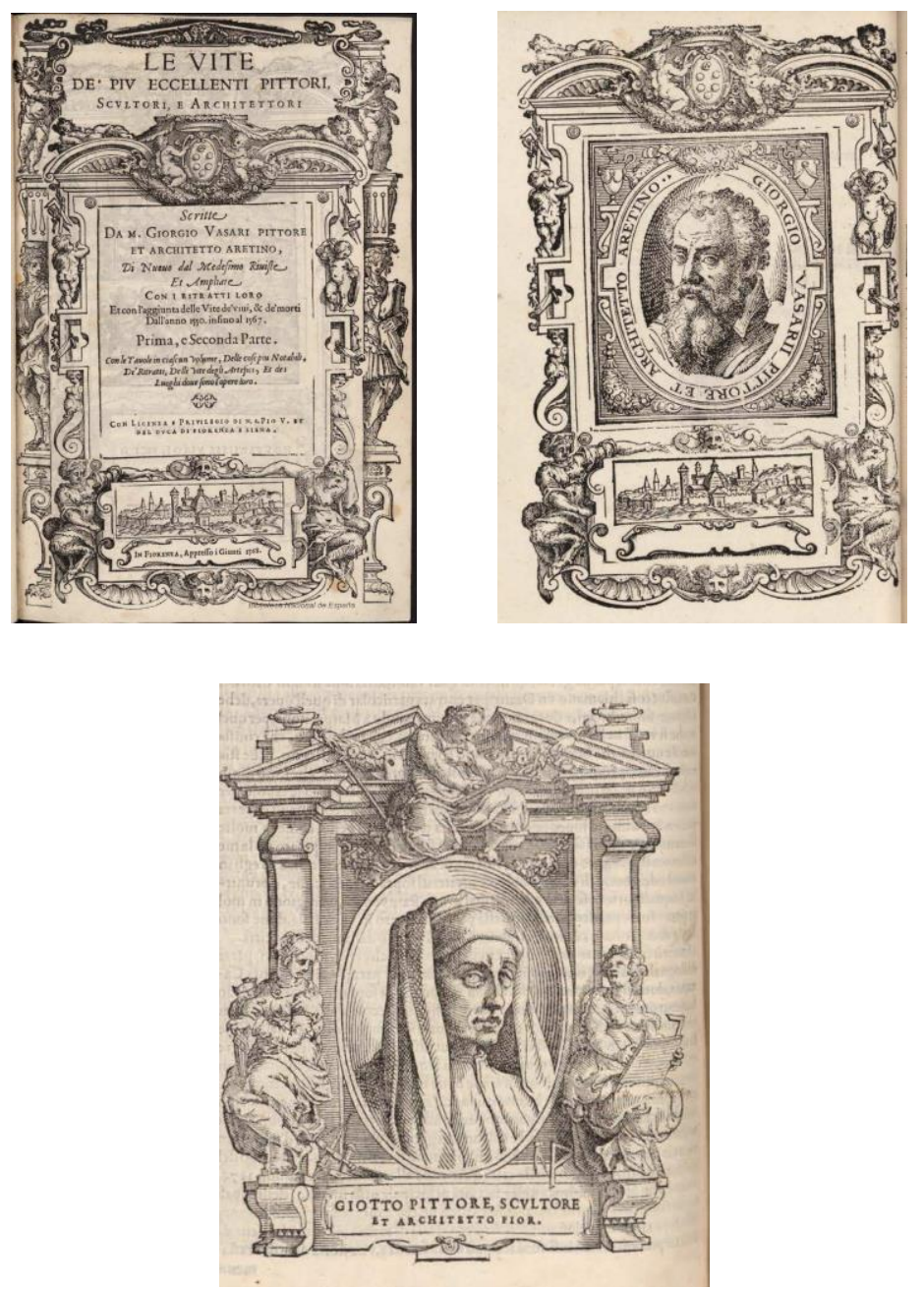

Giorgio Vasari, Le vite de piu eccellenti pittori, scultori e achitettori, Florencia, Giunti, $1568 .{ }^{11}$

La reutilización del taco de imprenta con un perfil urbano pasa de la portada a la base del retrato del autor inserto en los preliminares; como ocurría con los «retratos» del Flos sanctorum, entre otros ejemplos de la imprenta europea del siglo XVI, vistas urbanas incluidas (Eisenstein, 1983: 66 y 68), en el traslado la esquemática representación de la ciudad en la portada evoca a la Florencia de la imprenta de Giunti

$11<$ http://bdh-rd.bne.es/viewer.vm?id=0000186192\&page=1>. 
y, sobre todo, de los más notorios de los pintores celebrados en el volumen; cuando acompaña el retrato del autor podría ser la Arezzo que se menciona como origen de Vasari en la orla que enmarca su busto. Más que una muestra de pobreza de medios en el taller tipográfico, cabría interpretar el desplazamiento iconográfico como una apropiación del autor, para hacerlo hijo de un centro del campo cultural en el siglo XVI.

La incorporación del propio autor a los mecanismos de representación por medio de su retrato en los preliminares del libro se corresponde, en cierto modo, con la condición de pintor de Vasari, pero el lugar que ocupa y el tratamiento de la imagen denota un principio de autoridad, que en este caso fluye en una doble dirección: de los pintores a su biógrafo, y de este hacia quienes forman su museo, que es lo que permite su canonización, siendo el retrato uno de los factores más activos en esta consolidación.

Finalmente, con pequeñas diferencias de grado o de matiz, apreciamos la retórica visual compartida en la iconografía de los autores y el tratamiento de su imagen (Pommier, 2007). Se consagra la representación de busto, con un mayor detalle en los rasgos fisonómicos, lo que le otorga un aire de individualización a los retratos. Igualmente, se impone la inscripción en la forma ovalada que evoca los medallones antiguos, para trasladar el aura visual y conceptual de los auctores grecolatinos a los pintores italianos de los dos últimos siglos, en una dignificación de su arte y de su «excelencia» en el mismo. Al igual que sucede con los ropajes de los retratados, la inserción del retrato en un marco arquitectónico actualiza con su modelo estético la temporalidad, en una línea de continuidad entre la antigüedad clásica, el primer renacimiento florentino y un presente de Vasari en el que se van conformando los rasgos del manierismo. ${ }^{12}$

Tanto como en su retórica argumentativa, en esta obra fundacional encontramos ya fijada la estrecha relación entre la individualidad y la serie, la singularidad del artista y la dignidad del colectivo, en una mutua relación de intercambio de valores. El retrato individual se somete a la formalización «genérica» y se apoya en ella para resaltar su dimensión. La celebración del autor particular se realiza en estrecha relación, prácticamente de dependencia, con la formación del canon en todas sus dimensiones. Ejemplar y, hasta cierto punto, modelizadora resulta en este punto la sistemática empresa de Benito Arias Montano y Philips Galle, estratégicamente planificada y proyectada desde el foco editorial (y político) de Amberes. En sus cuidadas Virorum doctorum de disciplinis benemerentium effigies XLIII (1572) las notas biográficas prácticamente desaparecen; la vera effigies y la subscriptio versificada (los epigramas de Arias Montano) plasman sobre la página el modelo compositivo que caracteriza, en su unión de imagen y palabra, el género conformado sobre el modelo de Alciato. Como en los libros de emblemas más canónicos, la apuesta editorial de Galle lo es por un modelo humanista, orientado, ahora hacia un irenismo de tradición erasmiana, y por una

${ }^{12}$ Una consideración más detenida del panorama italiano de obras de este género nos llevaría a detenernos en los tempranos Elogia veris clarorum virorum imaginibus exposita quae in Musaeo Ionano comis spectantur (Venezia, 1546) de Paulo Jovio y alcanzar la serie de obras estudiadas por Sánchez García, 2013; valga citar entre ellos las obras de Scipione Mazzella (1597) Enrico Bacco (1602), Maurizio di Gregorio (1614) o Giovanni Antonio Summonte (1601-1643), predominantemente dedicados a reyes y figuras nobiliarias. 
expresión sintética, de intensidad casi conceptista y gran eficacia pragmática. ${ }^{13}$ Por todos los rasgos señalados, el volumen adquiere, en sus diversas acepciones, un carácter emblemático, en el que cabe apreciar que la ausencia de biografías perfila el valor de este elemento en la conformación del género discursivo-editorial.
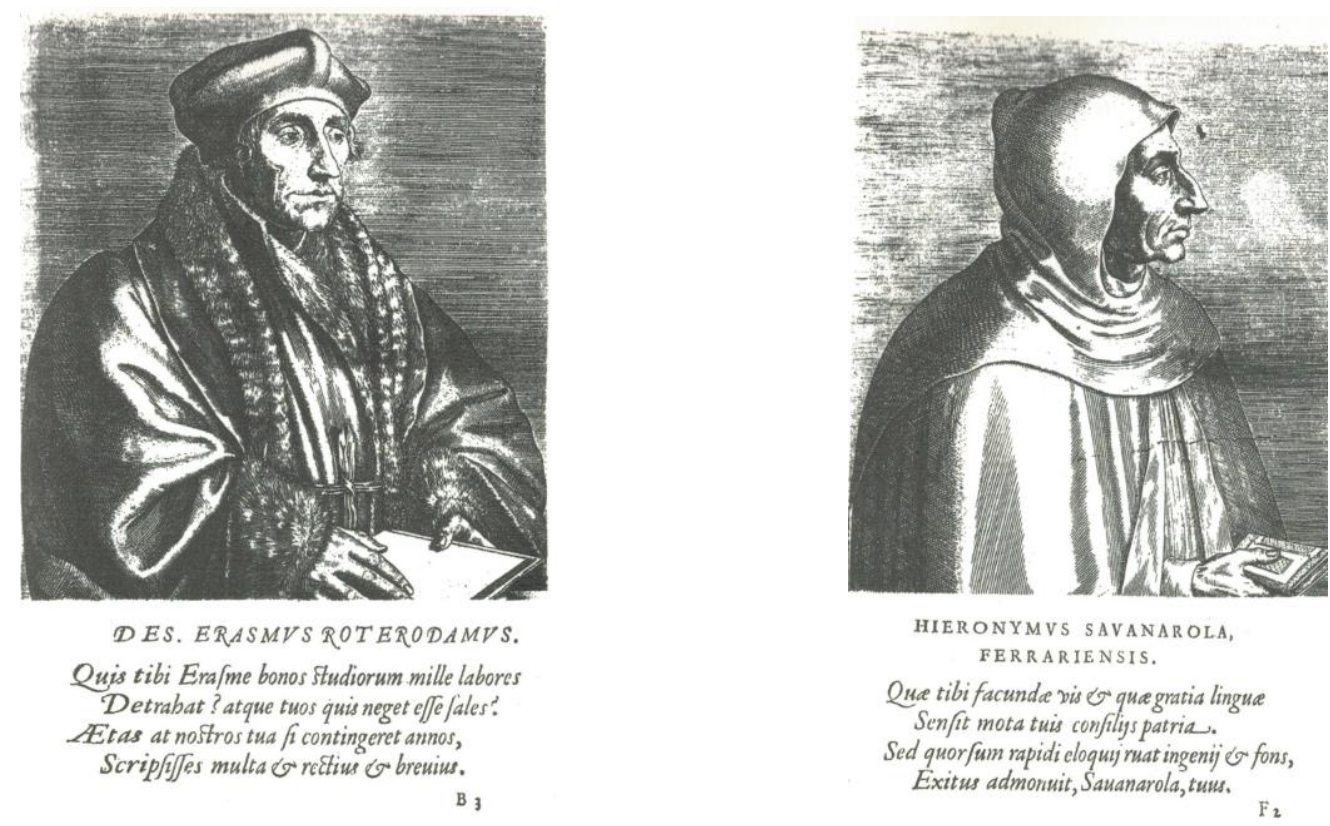

Arias Montano y Galle, 2005, pp. 147 y 209.

La extensión del modelo la confirma, en la no escueta tradición francesa de galerías de retratos y semblanzas, ${ }^{14}$ la dedicada, también en un contexto de guerras de religión, a los varones espirituales de uno y otro signo: Les vrais portraits des hommes illustres en pieté et doctrine. En sus páginas, un ejemplo, como el apartado dedicado a Savonarola, nos muestra la combinación de retrato, semblanza biográfica y composiciones en verso, para dejarnos a las mismas puertas del modelo de Pacheco, con

${ }^{13}$ Junto a las posibilidades que ofrece un impreso de dimensiones manejables, la omisión de un discurso biográfico de carácter expositivo y desarrollo de cierta amplitud permite eludir el compromiso de las referencias a cuestiones problemáticas en el plano de la ortodoxia doctrinal, propiciando una conciliación de figuras situadas en los diferentes vértices del mapa de una abierta guerra de religiones o en espacios de problemática intersección, como el Erasmo que parece inspirar un eje de la filosofía del libro y el Savonarola de reproducida inconografía; véanse imágenes e infra.

${ }^{14}$ Publicada póstumamente (Leiden, 1655-1656), la serie de recopilaciones biográficas de Pierre de Bourdeille, señor de Brantôme, muestran el carácter del género en las décadas finales del siglo XVI en lo relativo al interés por las compilaciones de vidas notables (McDonald, 2007), aunque con la ausencia de retratos y la diluida aparición de hombres de letras. En esos años la orientación hacia las representaciones visuales la recogen, de un lado, Antoine du Verdier, en La prosopographie ou description des personnes insignes, con sus retratos (Lyon, 1573; aumentada en 1605), y, de otro, André Thevet, con Les Vrais Portraits et vies des hommes illustres Grecs, Latins et Payens recuillis de leurs tableaux, livres, medailles antiques et modernes, Paris, 1584. En el siglo siguiente aparecen, entre otros, Les Portraits des hommes illustres françois qui sont peints dans la gallerie du Palais cardinal de Richelieu, avec leurs principales actions, armes, devises et éloges latins [...]. Ensemble les Abrégez. historiques de leurs vies, de Marc de Vulson de La Colombière (Paris, 1650), y La galerie des peintures ou Recueil des portraits et eloges en vers et en prose...Seconde partie (Paris, 1663). Véase EichelLojkine, 2001. 
la diferencia de la elección del perfil, en este caso muy característico y coincidente con el diseño representativo de la colección antuerpiense antes citada.
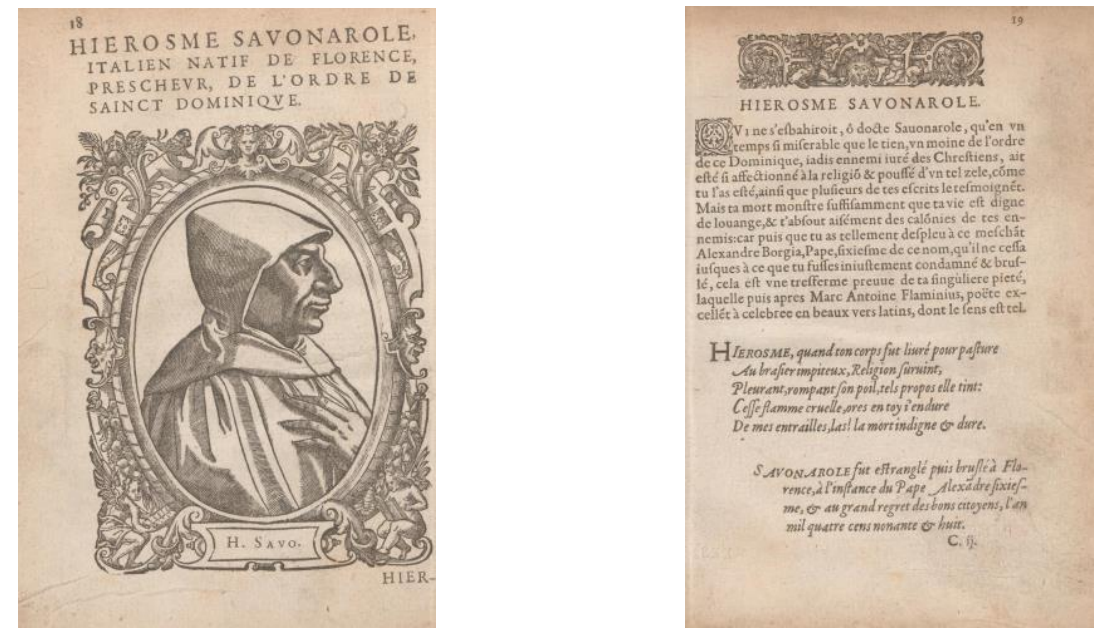

Les vrais portraits des hommes illustres en pieté et doctrine [...].Avec la description de leur vie et de leurs faits plus memorables. Plus quarante quatre emblemes chrestiens. Traduicts du latin de Theodore de Besze, Geneve, par Jean de Laon, $1581 .^{15}$

El carácter que aúna a los hommes illustres los acerca a la condición de los santos del Flos que en la misma cronología Villegas llevaba a su realización más reconocible y reconocida, y en este sentido la obra podría ejercer un papel de catalizador o, al menos, de muestra de la confluencia e intersección de elementos y tendencias en la definición de un género que en lo formal adquiere con obras como esta una representación paradigmática. Sin que nos planteemos la necesidad de una influencia directa en realizaciones posteriores, una colección de este tipo manifiesta el modo en que a lo largo de un siglo, a partir de mediados del XVI, se configura un patrón discursivo para la celebración de figuras relevantes, ofrecidas a modo de galerías en una combinación que incluye, junto a los versos, el retrato y la biografía. Su desarrollo se extiende en una dimensión europea (Hersant y Ramond, 2019), hasta conformar una reconocible modalidad genérica, cruzada por distintas líneas de fuerza, incluyendo miradas retrospectivas con valor renascimental y representaciones de una realidad más cercana para su exaltación o su reivindicación. El resultado es la definición, materialización y extensión de un imaginario y un modelo representativo que, si bien no se limita a este ámbito, tiene una manifestación particular en una incipiente república literaria, para cumplir en su desarrollo un papel fundamental. La conjunción de imagen plástica, relato de vida y manifestaciones poéticas cumple en el propósito de institucionalización letrada una función de gran relieve, acentuada por la repetición en forma seriada.

Así se lo plantea, para las letras sevillanas, Francisco Pacheco, sin que su condición de inédito le restara poder fecundante. Un siglo después, cuando López de Sedano se plantea la empresa de composición de un parnaso poético hispano del que

$15<$ http://dx.doi.org/10.3931/e-rara-12736>. 
extraer un canon nacional, volverá a hacer uso de los elementos constitutivos de las biografías ilustradas. Las similitudes y diferencias entre ambas obras nos hablan del devenir de la historia literaria, pero también del papel que en su conformación y desarrollo desempeñó esta modalidad genérica activada con la repetición seriada de sus componentes.

\section{EL CANON VISUAL PARA LOS POETAS ESPAÑOLES}

Tras haber destacado las diferencias en la compositio respectiva en las obras de Pacheco y de Sedano, y habiendo recompuesto en líneas someras el marco genérico en que podemos encuadrarlas, volvemos a los retratos y su gramática visual, también hecha de semejanzas y diferencias, de continuidades y modificaciones. Sobre ellas cabe apuntar algunas consideraciones relativas a la caracterización formal de un género (situándonos ahora específicamente en el del retrato) y en particular a su funcionamiento en el caso de los escritores y hombres de letras para contribuir a los proyectos de institucionalización.
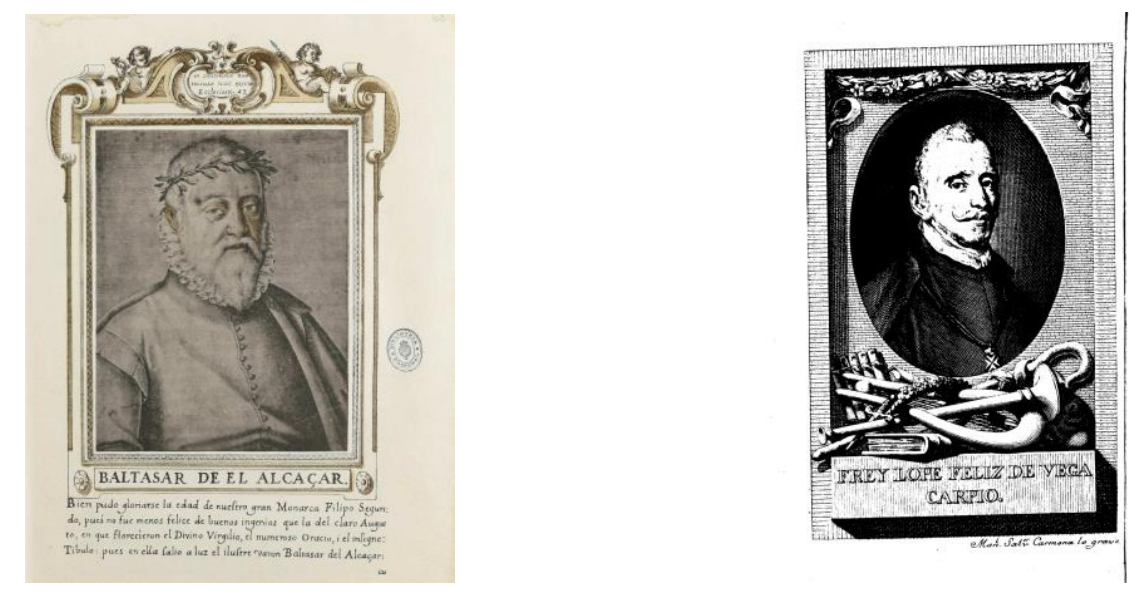

Como se aprecia en el dibujo de Alcázar por el pintor sevillano y el grabado de Lope en la obra dieciochesca, las simetrías entre los retratos plasmados por uno y otro se hallan en los elementos más específicos de la definición del retrato. Así, coinciden la elección del busto y la posición en que se representan los escritores, ${ }^{16}$ la combinación de rasgos personales propios de la fisonomía particular y la caracterización indumentaria que integra al personaje en un grupo, y, finalmente, el empleo del marco con valor

${ }^{16}$ La elección del busto como patrón iconográfico no carece de significación. Además de evocar los modelos de la antigüedad grecolatina, el recorte del cuerpo permite la omisión «natural» de las manos, lo que en el caso de los escritores de la España contrarreformista significaba obviar el escabroso debate acerca de la dignidad de su práctica como arte liberal, amenazada por la consideración de vil o «mecánica» que tenía la labor realizada con las manos (Gállego, 1976; Sánchez Jiménez y Sáez, 2018). El argumento se convirtió en central en el cuestionamiento y la defensa de la pintura, hasta que Velázquez lo resolvió con el gesto supremo de autorretratarse en el acto manual de la ejecución pictórica, reproduciendo el gesto de Cervantes en el prólogo del primer Quijote. Es de notar en la selección presentada que la única excepción es la del retrato de Savonarola en Les vrais portraits (supra), y el aire inquietante que tiene su mano-garra sobre el pecho bien puede pasar como una proyección del debatido y polémico carácter del extremo moralismo del predicador. 
retórico y pragmático, con independencia de las marcas estilísticas diferenciales entre la estética manierista y el patrón neoclásico. Se sintetizan en estas características compartidas la adopción de modelos clásicos, la habitual relación entre el individuo y la serie y, por último, la función de los elementos de canonización, aunque aquí sí con una gramática diferenciada.

Las variaciones se concretan en la economía de los atributos, con la sintética corona de laurel sobre la frente del poeta sevillano y, frente a ella, el despliegue analítico de los elementos simbólicos que, por metonimia, representan los géneros cultivados por el Fénix: el caramillo y la flauta (propios de la pastoral rústica o humilis), la lira (signo de la mediocritas de la lírica) y la trompa (vinculada a la epopeya sublimis); a estos instrumentos musicales se suman la daga y el libro, en clara alusión al tópico de armas y letras, pero también a la dualidad lopesca de vida activa y estudio, de biografía real y ficción literaria, que el escritor sintetizó de manera inigualable. La cruz de la orden de San Juan de Malta que el poeta luce al pecho, sobre los hábitos clericales, materializa el ascenso social de quien fue galardonado por los méritos de su pluma hasta alcanzar la condición de caballero, como culminación de su trayectoria.

Los objetivos de las estrategias en sus rasgos diferenciales también ofrecen signos de divergencia. Para Pacheco se trata de otorgar una forma de consagración; es significativo, en el caso de Baltasar del Alcázar, que fue un autor inédito hasta su muerte, lo que parece indicar que el pintor sevillano escribía fundamentalmente para su círculo, el de quienes conocían al poeta, aunque, como en la mayor parte de los varones retratados, no hubiera pasado por la imprenta. Para el neoclásico Sedano el objetivo que se impone es el de la categorización, mostrando a un Lope cultivador de géneros dispares, todos ellos reducidos a los patrones clásicos, en una clara orientación de los efectos de recepción y lectura de un autor que podía ser problemático por su ruptura de las reglas. Inscrito en el medallón clásico, enmarcado en una hornacina de corte dórico y ornado con la guirnalda, el poeta ve en gran medida neutralizadas sus peculiaridades y los rasgos menos reductibles al orden académico, que se impone en la serie de representaciones y su regularidad iconográfica y visual.

Alejados de la cercanía temporal por más de un siglo, los retratos se convierten en el Parnaso de Sedano en una forma se afirmación del parnaso colectivo que quiere poner ante el lector para incidir en el debate sobre el valor de la tradición previa y la pretendida decadencia en el período áureo (Molina Huete, 2013). En esa regularidad de los elementos de representación, que avanzan sobre los propuestos por Pacheco, queda espacio para unos rasgos de individuación y de singularidad caracteriológica, como puede apreciarse en el tratamiento del rostro de Góngora. 


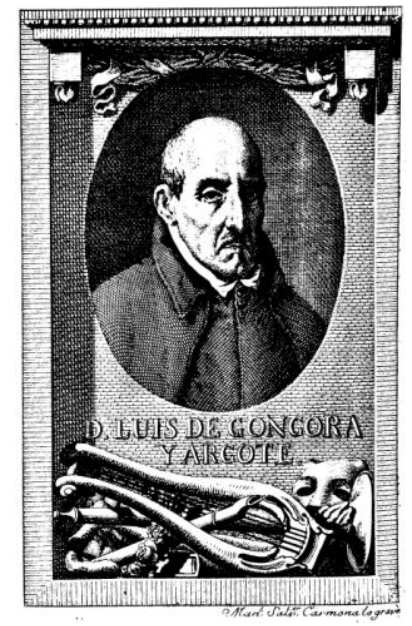

Su fisonomía se apoya en una tradición asentada a través de los grabados de Juan van der Hamen y Jean de Courbes, y en gran medida en el óleo de Velázquez. Más allá de lo que en ella puede haber de fidelidad al original, a la vera effigies del personaje, el gesto dibujado acentúa, en su aire sombrío y taciturno, la identidad con una poesía marcada por la dificultad y la oscuridad, en claro contraste con la bonhomía del semblante de Alcázar, propio de su poesía de la «graciosidad» o «de la sal» (Bonneville, 1969; Núñez Rivera, 2012), o el atractivo seductor de Lope, aún con vestigios en su ancianidad. Todas ellas son imágenes que se corresponden con los juicios sobre la poesía de cada uno de ellos, y la atención a esta circunstancia nos ayuda a valorar mejor el papel de la imagen en el discurso de institucionalización de la poesía y de las letras, con especial relevancia en el caso de estas obras mixtas, con parte de antología y con mucho de una galería de biografías ilustradas. Con ellas, entre otros discursos confluyentes, la representación de una república letrada se eleva al rango de un parnaso canónico y canonizador. De camino, la incorporación de los vultos retratados contribuye decisivamente a la consolidación de un imaginario, en el que los escritores pueden equipararse con otros grupos de dignidad indiscutible (reyes, héroes, santos), a la vez que se perfilan en ellos los rasgos de la individualidad.

\section{LA CONSTRUCCIÓN DE UN DISCURSO}

Es hora de establecer algunas conclusiones, por más que lo esquemático del panorama esbozado (más bien unas calas de cierta significación) no permita elevarlas al rango de definitivas y de alcance general.

A través de algunos hitos, han quedado apuntados los rasgos de un discurso a la vez genérico y pragmático. Las marcas formales articuladas en torno a la confluencia de retratos, semblanzas y textos poéticos establecen un aire de familia para esta diversidad de manifestaciones, permitiendo su agrupación en una modalidad de valor genérico. La similitud de sus intenciones y la compartida finalidad de sancionar el reconocimiento de un grupo, vinculado a través del tiempo o concentrado en un espacio, los emparenta con otras formas discursivas y los sitúa en una estrategia de construcción de un campo y de regularización de los mecanismos para la inserción en el mismo. Como ocurre en la 
tradición, la serie se constituye como tal y se compone a partir de la dialéctica de continuidad y variaciones; la primera determina la agrupación en el paradigma del género; las segundas señalan el orden sintagmático de la historia, con la distancia que separa, por ejemplo, la Sevilla posthumanista y cultista que sirve de escenario y referencia a la empresa de Pacheco y, de otro lado, la España inmersa en el debate sobre la restauración o renovación de las letras nacionales y su reconocimiento en un horizonte europeo (Checa Beltrán, 1998 y 2014).

A la luz de los elementos considerados, y en términos de historiografía literaria y de constitución del canon, podemos señalar en los casos presentados una serie de estrategias y objetivos compartidos, que abordamos en primer lugar. En el eje articulador se halla la insistencia en el establecimiento de un parnaso, que paulatinamente tiende a la condición de canon; su valor es plenamente actuante cuando, como postula López de Sedano en su Parnaso, se propone como modelo para la poesía del presente al mismo tiempo que como una reivindicación de la tradición pretérita. ${ }^{17}$ En su proceso de construcción el parnaso representado se muestra de manera simultánea e inseparable como un marco colectivo e individual; el primer rasgo es requisito imprescindible, de acuerdo con el patrón mitológico y clásico, y refuerza en la cantidad - y en una cierta forma de identidad grupal - la propia entidad del concepto axiológico y de su realidad; constituida la serie y garantizada la adscripción a la misma, el escritor puede ver remarcada su individualidad: sin ser un sujeto aislado, sino reafirmado en el conjunto, puede asentar y desarrollar su identidad propia, que, a su vez, enriquece el panorama colectivo. Así se aprecia de modo particular en la antología de Sedano, donde los retratos destacan a los autores más relevantes, sobresalientes en el horizonte de un conjunto mucho más amplio. La jerarquía, pues, establece la articulación entre el conjunto y el individuo y se proyecta en la empresa canonizadora como un rasgo procedente del monte de Apolo.

Un componente esencial en la naturaleza y condición de este parnaso «moderno» es la delimitación de un espacio geográfico que es en esencia un ámbito cultural, un cronotopo literario, si se nos permite usar el término de Bajtin como matizado sinónimo de la noción de Bourdieu. De forma implícita, en el caso de Pacheco el marco y el referente de los «varones ilustres» es de manera prioritaria y casi absoluta el del entorno académico sevillano desde las últimas décadas del siglo XVI, incluyendo también en él personajes relevantes, como Lope, que estuvieron vinculados en algún momento de su vida a la ciudad del Guadalquivir y en relación directa con algunos de sus más señeros habitantes. En la antología de Sedano esta marca queda explícita, y por partida doble (españoles/castellanos), ya desde la portada, y en ello insiste el recopilador en sus textos preliminares, con su declaración de la utilidad de la recopilación para sus compatriotas. Menos expresa queda en la denominación la referencia a la cronología que abarca, aunque las declaraciones paratextuales, así como la propia selección, la sitúa de manera

17 «Para la [noticia] que necesita el público de la presente colección, basta advertir que en ella se le proporciona un cuerpo de las mejores poesías castellanas, que en adelante pueda servir de modelo para fijar el buen gusto de la Nación sobre esta parte de nuestra bella literatura en todas y en cada una de sus especies» (López de Sedano, 1768: iii-iv; modernizo grafía y puntuación y conservo cursiva original). 
inequívoca en el conjunto de los siglos XVI y XVII, ${ }^{18}$ que Velázquez había querido deslindar en sus Orígenes de la poesía española (1754) en una contrapuesta segmentación entre un momento de plenitud (el «siglo de oro» sensu stricto) y otro de decadencia, a lo que el Parnaso da la réplica.

El efecto de la vinculación con un marco temporal y, sobre todo, espacial confiere a la serie de obras y autores los rasgos que identifican una república letrada, con sus relaciones y sus tensiones internas, en diálogo continuo, en lo que incide la señalada naturaleza repetitiva en los elementos de representación visual, como cabe también apreciar en la retórica de los relatos biográficos. La confluencia de retratos, semblanzas y textos escogidos de autores seleccionados desplaza este concepto hacia su valor más connotativo, como textos y autores selectos. Frente a la voluntad esencialmente acumulativa de cancioneros y romanceros, la antología de Sedano manifiesta una evidente opción por una poética «culta», ya destacada también por Pacheco. No es baladí la adjetivación empleada respectivamente al referirse a los «célebres poetas» y los «varones ilustres» que acogen en sus volúmenes. La inclusión de autores y obras en las respectivas compilaciones no es mucho más significativa que sus omisiones. Como cabría formular en términos estructuralistas, el canon se define por oposición a lo que queda excluido por la condena explícita o el silencio. En términos de la sociología de Bourdieu, asistimos en estos casos a la definición de un centro y su implícito rechazo de la periferia.

En definitiva, el modelo genérico que representan estas obras no solo se dirige a la construcción de un canon, sino que lo hace estableciendo los rasgos que lo definen como tal, en los valores que expresamente subraya en las semblanzas y su ilustración plástica y en los que se imponen en la selección de los textos.

Las estrategias compartidas y el tronco retórico común no neutralizan, sino que subrayan, unas diferencias específicas donde los matices en la realización genérica traslucen la distancia histórica entre el pintor académico sevillano y el antólogo en la corte neoclásica, con sus respectivos propósitos de canonización, fuertemente marcados por su historicidad.

La divergencia más evidente atañe al ámbito geográfico-cultural acotado, acordados respectivamente a tiempos y situaciones políticas distanciadas. El carácter fuertemente localista del panteón manuscrito de Pacheco arraiga en una concepción de base humanista y deriva tardía, donde se decanta la amplia tradición de antigüedades y encomia urbium, muchas de ellas en el ámbito hispánico incluyendo galerías de hombres ilustres (Osuna, 2006) progresivamente pobladas por individuos del nuevo grupo letrado. En el horizonte imperial, de un lado, y el ideal de la república ciudadana del Quattrocento italiano, de otro, se dibuja una cultura urbana de ámbito local y perfil académico, reunión de contemporáneos con lazos personales, estrategias compartidas o

${ }^{18}$ López de Sedano incluye también composiciones del siglo XVIII (con autores como Ignacio de Luzán, con 9 poemas en los tomos II, IV y V; el conde de Torrepalma, en el tomo III, con un texto «con que se continúa el proyecto de ofrecer composiciones de poetas clásicos de nuestros días» (vi), o Manuel Pellicer de Velasco, cuyo poema «en su línea es una composición original que basta a acreditar su ingenio y también la restauración del buen gusto en nuestro tiempo si hallasen otras producciones más dilatadas de su feliz pluma» [III: viii]). 
complementarias y rasgos de comunidad, cuya sociabilidad ostentosamente mostrada se convierte en un elemento de afirmación y consolidación. El círculo creado puede prolongarse en el tiempo, en generaciones enlazadas, a modo de actualización del arquetipo de la academia, incluso con la actividad de quien actúa a su cabeza; no es otro el papel de Pacheco al levantar acta de la existencia de este grupo, su constitución de un entorno y la textualización de la trama de relaciones o vínculos letrados que lo sustentaba. En ello no se distanciaba de prácticas complementarias en su quehacer, como al compilar una selección de sus manifestaciones poéticas o textuales o, en general, al actuar a modo de dinamizador de la actividad del grupo y su autofiguración, según realizó también al reeditar pro domo sua los versos del ancestro Herrera.

Frente a este modelo cultural y discursivo, López de Sedano sitúa su Parnaso en una compleja encrucijada, estrechamente ligada a la configuración de lo nacional, cuando en la decadencia del imperio la cultura vuelve a acudir en ayuda de las armas, en una nueva diplomacia de las letras (Fumaroli, 2011). En las coordenadas de la ilustración, en un eje, y el neoclasicismo, en el otro, un sentido de lo nacional que se acerca a grandes pasos a su configuración definitiva en las décadas siguientes ha de definirse respecto a su contexto europeo, pero también en relación con su pasado. Ambas vertientes se aúnan en el debate sobre el valor de la tradición poética castellana y su vigencia para el momento presente y su expresión literaria. En este escenario la obra de Sedano se concibe en clave nacional y con una esencial dimensión histórica, acordes con el propósito de afirmación del valor de un pasado con voluntad inclusiva, frente a los anatemas levantados desde la ortodoxia neoclásica, de Velázquez a Tomás de Iriarte (Ruiz Pérez, en prensa b). La neutralización de diferencias se manifiesta en los criterios de ordenación, ajenos a la articulación cronológica o la agrupación de textos por «escuelas» o aun por autores, lo que rompe la presunta distancia entre dos siglos y dos modelos estéticos o, como se pretendía, un momento de plenitud y su degradación. Ello permite dibujar una tradición nacional sin fisuras, valiosa en su conjunto y en su articulación en torno al paradigma de Villegas (que abre la antología) y su posición de eje cronológico y estético, sin cuestionamiento mayor por parte del academicismo neoclásico

De esta primera diferencia depende la apreciable en la economía organizativa de los elementos textuales y plásticos combinados. La regularidad sistemática del códice de Pacheco plasma un discurso de la identidad común inter pares, reflejada en una iconografía regularizada y homogeneizada y en una prosopopeya que en su brevedad elude los elementos de singularización. Y a la misma intención responde la reducción al mínimo de la faceta antológica, pues este relativo silencio iguala a aquellos que contaban con una obra impresa de cierta amplitud y a quienes reducían sus huellas textuales a la oralidad académica o al restringido manuscrito. Como en los dibujos el tratamiento generalizador subordina los rasgos de la fisonomía individual a la regularidad del formato y el marco arquitectónico del retrato, la práctica reducción de los versos a los cruzados a modo de elogio entre los moradores de este parnaso local nos habla de un círculo con rasgos de endogamia casi esotérica, que impone su dimensión colectiva como elemento de afirmación de mayor contundencia que la altura de algunas singularidades. 
En Sedano la amplitud de los criterios selectivos y la extensión misma de una obra que aún en el tomo IX se presenta como inacabada desempeñan un papel similar, aunque ajustado a la clave nacional española ostentada desde la portada. Al multiplicar las muestras textuales (a la inversa que Pacheco) insiste en el argumento de una presencia colectiva, sostenida a través de los siglos, en estrecho diálogo interno y con un valor en el que los matices se convierten en factores de complementación. Lo que pudiéramos llamar una retórica cuantitativa y su perspectiva diacrónica permiten complementar la antología de poemas con los elementos de discriminación que suponen las biografías y, sobre todo, los retratos grabados. Las primeras son más generalizadas, pero hay una gran distancia entre las más extensas y las más breves, coincidiendo casi siempre con un implícito juicio de calidad. Mucho más selectos, los retratos establecen una jerarquía evidente que reorienta la horizontalidad de la república letrada sevillana, plasmada al modo humanista por Pacheco, hacia la verticalidad de una implícita noción de canon construida sobre la iconografía y los valores de un Parnaso donde las cumbres comparten espacio con las faldas, pero con notorias diferencias axiológicas.

Las coincidencias y discrepancias en el empleo de estos tres elementos (imagen, biografía y textos) y la persistencia de su empleo en confluencia denotan su condición de partes de una gramática argumentativa en la configuración de la institución letrada y sus protagonistas, con un paradigma de componentes combinables en una sintaxis particularizada, para formar un lenguaje común con enunciados diferenciables. Su articulación resulta de extremada coherencia en un proceso donde caminan en paralelo los procesos conjuntos de institucionalización de una práctica y del conjunto de sus cultivadores y la construcción de las respectivas individualidades.

En relación con ello resulta también complementaria la dualidad de sincronía y diacronía apreciable en la consideración conjunta de las obras de Pacheco y de Sedano. En la primera domina un principio de contemporaneidad, en la que el compilador afirma a la vez su condición de creador (de retratos) y de testigo (aval de su condición de «verdaderos»). En el Parnaso español se impone la perspectiva histórica, pero también crítica, en directa respuesta a la excluyente noción de «siglo de oro» fijada en los Orígenes de la poesía castellana (1754) de Velázquez; Sedano ya no se pretende sujeto de un trato directo con los autores, sino juez que dictamina sobre el valor de una obra que puede ser recuperada de su condición de pasada para forjar otro modo de identidad colectiva con función de modelo. La afirmación de Pacheco tiene una dimensión cercana a lo que dos siglos después será un manifiesto: un acta de nacimiento y programa de escuela, una afirmación colectiva en busca de instauración de un espacio propio dentro del campo cultural; de ahí su carácter selectivo y marcadamente identitario, para sustentar una diferencia específica en el marco de las letras hispanas. La reivindicación de Sedano, complementariamente, se acerca a lo que será una historia literaria, aunque menos por su inequívoco valor retrospectivo que por lo que tiene de voluntad inclusiva, de definición de un campo completo antes de reconocer y valorar la diversidad de sus componentes. Sin la condición de acta de defunción vinculada a una labor meramente arqueológica, el Parnaso se afirma más bien como un documento de identidad que acredita la condición nacional y propone una integración con sentido de proyecto, de proyección de futuro: el reconocimiento de un abarcador «siglo de oro» se 
propone como factor de palingenesia, como fermento para la restitución de un prestigio y su renovación en el presente.

Asistimos, pues, con la coherencia de todos los factores que hemos distinguido entre estas dos empresas de referencia, a un discurso históricamente conformado, donde la articulación de las biografías ilustradas transcurre entre la afirmación de un parnaso diferenciado, el de la Sevilla entre dos siglos, y la ostentación de un canon clásico nacional, con tanta condición de respuesta a los ataques y cuestionamientos ajenos ${ }^{19}$ como de llamada a una conciencia hispana sobre su tradición y su potencialidad renovadora. Al menos con carácter metodológico, cabría proponer el trazado entre estos dos puntos focales como una etapa casi conclusiva en el proceso de conformación de la república literaria, en confluencia de los mecanismos de afirmación autorial individual y las estrategias de institucionalización y canonización.

Retomando las premisas con que se abrían estas páginas, tras contrastar con los hechos concretos su posible validez generalizadora, cabría proponer algunos matices, más que para reformularlas, para pasar del nivel teórico al de una realidad histórica, por más que en la enunciación tengamos que retomar un cierto esquematismo. Desde él cabe decir que la distribución de posiciones en el campo literario requiere previamente la constitución de dicho campo, en el que la percepción de dos realizaciones (la local y la nacional, la de la contemporaneidad y la historiográfica) no implica una disyuntiva, sino una complementación de planos articulados: el campo académico sevillano se nos presenta de mano de Pacheco a modo de empresa de self-fashioning colectivo, entre la singularización y el reconocimiento en el parnaso de la poesía española del siglo XVII en una dialéctica que reproduce la de los autores incluidos en sus páginas, con unas biografías ilustradas que resaltan su condición de ilustres.

Los mecanismos del panteón de Pacheco y la antología de Sedano resultan reveladores de la estrategia de las series en la república letrada, que pasan por la afirmación de un grupo camino de la historia literaria: el grupo establece la categoría, al tiempo que los sujetos que lo forman se reconocen como individuos en la semejanza con sus iguales, sin que los mecanismos de distinción neutralicen, antes bien, las refuerzan, las claves de una identidad colectiva. La disposición seriada de las biografías ilustradas es el síntoma de esta consideración y, a la vez, uno de sus impulsos más definitivos, al visibilizar de forma paralela el sujeto colectivo y sus componentes individuales y al establecer una intensa dialéctica de similitudes y diferencias tan propia de los procesos de afirmación como del funcionamiento mismo del campo literario, revelando que su proceso de conformación interviene directamente en la definición de sus rasgos caracteriológicos.

De la misma manera, apreciamos que la construcción del canon colectivo, en una realización prácticamente integral en la obra de Sedano, se muestra estrechamente ligada a la conformación de una imagen de autor, tal como se evidencia de manera paradigmática en la sostenida tradición iconográfica del retrato y sus elementos de

${ }^{19}$ Se incluyen, de manera más o menos implícitas, las críticas de un neoclasicismo considerado extranjerizante, que López de Sedano deja entrever en el «Prólogo» de su primer volumen, al enfrentarse al «poco aprecio con que generalmente se mira la erudición nacional, de que resulta la ignorancia de muchos ilustres escritores españoles y la indiscreta inclinación a los estranjeros» (1768: i-ii). 
connotación, pero también en el modelo retórico y pragmático de sus semblanzas biográficas, así como la aplicación selectiva o no del mismo. Con ellas se materializa una función compartida en modalidades histórico-culturales diferenciadas, que se mueven en nuestro caso entre el entorno académico en que se inscribe el propio autor de su modelización y la construcción de un pasado patrio en respuesta a su cuestionamiento. En los dos casos la notable homogeneidad en el tratamiento de los retratos y el similar patrón retórico de las biografías, con la resultante de la galería de semblanzas ilustradas, nos permite extraer como conclusión que el establecimiento de la serie implica la determinación de los rasgos necesarios para integrarla, los requisitos que ha de cumplir un individuo (más que su obra) para poder inscribirse en la misma, en una dialéctica de sostenimiento mutuo. La corona de laurel para los retratos dibujados por Pacheco o el sistemático paradigma de atributos a los pies de los grabados del Parnaso para canonizar al autor en el cultivo de unos géneros determinados cumplen esta función, reconociendo en cada personaje su condición autorial en paralelo a su reforzamiento de la serie establecida. En no pocos casos los letrados sevillanos agrupados por Pacheco no contaban con obra publicada ni con títulos acabados, por lo que es el tratamiento de su vida e imagen en el Libro de descripción de verdaderos retratos lo que los convierte (o, al menos, los sanciona como tales) en «ilustres y memorables varones». Incluso en el Parnaso, la existencia misma de los textos poéticos y su impresión dieciochesca no alcanzan por sí solos la dimensión canónica otorgada por la «Noticia» en la que se condensa la vida de un autor $y$, en los casos más destacados, el retrato que la ilumina.

Mientras que la labor bibliográfica que para el caso español supone la tarea iniciada por Tamayo de Vergas (Junta de libros, ms. de 1624) y coronada por Nicolás Antonio (Bibliotheca Hispana Vetus, 1672, y Nova, 1696, póstuma) acerca la relación entre la obra y el escritor al sentido moderno (anterior al simbolismo y la vanguardia), en el que es lo escrito (y publicado) lo que determina la condición autorial del segundo, las series de biografías ilustradas como las consideradas aquí arraigan en la mentalidad ligada al sentido clásico de la auctoritas, en la que esta es la que se proyecta sobre el propio texto desde el prestigio del autor. Sin embargo, o quizá por esa posición intermedia, cumplen una función determinante en la construcción del canon y, antes que esta, en la formación del campo literario a partir de la materialización de una república letrada. Junto a la antología, y reforzando su eficacia canonizadora, la biografía y el retrato autoriales, en especial con los efectos derivados de su articulación, en galerías de semblanzas ilustradas, representan la bandera más visible y uno de los instrumentos más eficaces en la construcción del canon autorial.

\section{OBRAS CITADAS}

Álvarez Amo, Francisco Javier (2008), «Significado y función de los catálogos de poetas españoles del siglo XVI», en Begoña López Bueno (dir.), El canon poético en el siglo XVI, Sevilla, Universidad de Sevilla, pp. 305-322. 
Álvarez Amo, Francisco Javier (2010), «Significado y función de los catálogos de poetas españoles del siglo XVII», en Begoña López Bueno (dir.), El canon poético en el siglo $X V I I$, Sevilla, Universidad de Sevilla, pp. 215-234.

Aradra, Rosa M. ${ }^{a}$ y Cesc Esteve (eds.) (2017), Lecturas al margen: canon e interpretación en la Edad Moderna, monográfico de Arte nuevo, 4. <http://www.artenuevorevista.com/index.php/arte-nuevo/issue/view/4 >.

Arias Montano, Benito y Philips Galle (2005), Virorum doctorum de disciplinis benemerentium effigies XLIII, ed. Luis Gómez Canseco y Fernando Navarro Antolín, Huelva, Universidad de Huelva.

Bassegoda i Hugas, Bonaventura (introducc.) (1990), Francisco Pacheco, Arte de la pintura, Madrid, Cátedra.

Boillet, Danielle, Marie-Madeleine Fragonard et Hélène Tropé (eds.) (2012), Écrire des vies: Espagne, France, Italie XVIe-XVIIIe siècles, Paris, Presses Sorbonne Nouvelle.

Bonneville, Henry (1969), Le poète sévillan Juan de Salinas (1562?-1643): vie et oeuvre, Paris, Presses Universitaires de France.

Bourdieu, Pierre (1995), Las reglas del arte. Génesis y estructura del campo literario, Barcelona, Anagrama.

Bradford, Richard (ed.) (2018), A Companion to Literary Biography, Chichester, Wiley Blackwell.

Buiguès, Jean-Marc, «La imagen del autor entre miniaturas y grabados (1450-1650): del copista al humanista», en Pedro Ruiz Pérez, en prensa a.

Cacho Casal, Marta P. (2011), Francisco Pacheco y su «Libro de retratos», Sevilla-Madrid, Fundación Focus Abengoa-Marcial Pons.

Checa Beltrán, José (1998), Razones del buen gusto. Poética española del neoclasicismo, Madrid, CSIC.

Checa Beltrán, José (2014), Demonio y modelo. Dos visiones del legado español en la Francia ilustrada, Madrid, Casa de Velázquez.

Davis, J.C. e Isabel Burdiel (eds.) (2005), El otro, el mismo. Biografía y autobiografía en Europa (siglos XVII-XX), València, Universitàt de València.

Dubel, Sandrine y Sophie Rabau (eds.) (2001), Fiction d'auteur? Le discours biographique sur l'auteur de l'Antiquité à nos jours, Paris, Honoré Champion.

Eco, Umberto (2009), Vertigine della lista, Milano, Bompiani.

Eichel-Lojkine, Patricia (2001), Le siècle des grands hommes. Les recueils de Vies d'hommes illustres avec portraits du XVI siècle, Louvain, Peeters.

Eisenstein, Elizabeth (1983), La revolución de la imprenta en la edad moderna europea, Madrid, Akal.

Ferguson, Margaret W. (1983), Trials of Desire. Renaissance Defenses of Poetry, New HavenLondon, Yale University.

Ferrari, Federico et Jean-Luc Nancy (2005), Iconographie de l'auteur, Paris, Galilee.

Foucault, Michel (1969), «Qu'est-ce qu'un auteur?», Bulletin de la Société Française de Philosophie, 63, 3, pp. 73-104.

Fumaroli, Marc (2011), La diplomacia del ingenio. De Montaigne a La Fontaine, Barcelona, Acantilado.

Gállego, Julián (1976), El pintor, de artesano a artista, Universidad de Granada (reed. 1995, Diputación de Granada).

García Aguilar, Ignacio (2006), «Varones nobles y nobles poetas: los repertorios de ingenios en el Siglo de Oro», en Begoña López Bueno (dir.), En torno al canon: aproximaciones y estrategias, Sevilla, Universidad de Sevilla, pp. 285-316.

García Aguilar, Ignacio y Adrián J. Sáez (eds.) (2016), "Auctor in fabula». Imágenes y representaciones autoriales en el Siglo de Oro, monográfico de Studia Aurea, 10. $\langle$ https://studiaaurea.com/issue/view/v10 $>$.

Greenblatt, Stephen (1980), Renaissance Self-Fashioning. From More to Shakespeare, Chicago, Chicago University.

Hersant, Marc y Catherine Ramond (eds.) (2019), Les protraits dans le récits factuels et fictionnels de l'époque classique, Leiden-Boston, Brill-Rodopi. 
López Bueno, Begoña (1989), «Las escuelas poéticas españolas en los albores de la historiografía literaria: Arjona y Reinoso», Philologia Hispalensis, 4,1, pp. 305-318.

López Bueno, Begoña (1992), «Para la historiografía decimonónica de la "Escuela poética sevillana" del Siglo de Oro: unas reflexiones», en Mosaico de varia lección literaria en homenaje a José Ma Capote Nebot, Sevilla, Universidad de Sevilla, pp. 87-91.

López de Sedano, Juan José (1768-1778), Parnaso español, Madrid, Joaquín Ibarra-Antonio de Sancha.

Lorenzo Álvarez, Elena de (ed.) (2017), Ser autor en la España del siglo XVIII, Gijón, Trea.

Manero Sorolla, M ${ }^{a}$ Pilar (1983), «Antologías poéticas italianas de la segunda mitad del siglo XVI (1545-1590)», Anuario de Filología, 9, pp. 259-299.

McDonald, Katherine M. (2007), «Colorer les faits: le statut du portrait graphique chez Brantôme», Seizième Siècle, 3, pp. 207-233. 〈https://www.persee.fr/doc/xvi_17744466_2007_num_3_1_925>.

Molina Huete, Belén (2013), «La poesía del Siglo de Oro a la luz del Buen Gusto: el Parnaso español de López de Sedano», en José Lara Garrido y Belén Molina Huele (eds.), Estudios sobre la recepción y el canon de la literatura española (II). La poesía del Siglo de Oro en el siglo de las luces, Madrid, Visor, pp. 39-99.

Montero, Juan (2016), «El pintor Pacheco y las letras sevillanas del Siglo de Oro (con unas notas sobre su producción poética)», en $\mathrm{M}^{\mathrm{a}}$ del Valme Muñoz Rubio e Ignacio Cano Rivero (coords.), Pacheco: teórico, artista, maestro (1564-1644), Sevilla, Consejería de Cultura de la Junta de Andalucía, pp. 25-36.

Montero, Juan y Marta P. Cacho Casal (2014), «Francisco Pacheco, editor de Obras de Fernando de Herrera: análisis de un documento inédito», Bulletin of Spanish Studies, 91,4, pp. 491504.

Montero, Juan y Antonio Sánchez Jiménez (eds.) (2017), Carrera literaria y representación autorial en la literatura del Siglo de Oro, monográfico de eHumanista, 35. $<$ https://www.ehumanista.ucsb.edu/volumes/35>.

Núñez Rivera, Valentín (2012), «Hacia un doble paradigma. Lírica ornada y poética familiar», en Begoña López Bueno (dir.), La «Idea» de la poesía sevillana en el Siglo de Oro, Sevilla, Universidad de Sevilla, pp. 197-254.

Osuna, Inmaculada (2006), «Las ciudades y sus "Parnasos": poetas y "varones ilustres en letras" en la historiografía local del Siglo de Oro», en Begoña López Bueno (dir.), En torno al canon: aproximaciones y estrategias, Sevilla, Universidad de Sevilla, pp. 233-283.

Özmen, Emre y Tania Padilla Aguilera (ed.) (2019), El autor en la modernidad, monográfico de Theory Now, 2,1. 〈http://revistaseug.ugr.es/index.php/TNJ/issue/view/609/showToc>.

Pacheco, Francisco (1985), Libro de descripción de verdaderos retratos de ilustres y memorables varones, ed. Pedro M. Piñero y Rogelio Reyes, Sevilla, Diputación Provincial de Sevilla.

Pask, Kevin (1996), The Emergence of the English Author: Scripting the Life of the Poet in Early Modern England, Cambridge, Cambridge University.

Piper, David (1982), The Image of the Poet: British Poets and theis Portraits, Oxford, Oxford University.

Pommier, Édouard (2007), «Il ritratto di artista nell'arte italiana del XVI secolo. Saggio di tipologia», en Aldo Galli, Chiara Piccinini, Massimiliano Rossi (eds.), Il ritratto nell'Europa del Cinquecento. Atti del Convegno (Firenze, 7-8 novembre 2002), Florencia, pp. 3-28.

Residori, Matteo, Hélène Tropé, Danielle Boillet et Marie-Madeleine Fragonard (eds.) (2014), Vies d'écrivains, vies d'artistes. Espagne, France, Italie, XVIe-XVIII siècles, Paris, Presses Sorbonne Nouvelle.

Romero Tobar, Leonardo (ed.) (2008), Literatura y nación: la emergencia de las literaturas nacionales, Zaragoza, Prensas Universitarias de Zaragoza.

Ruiz Pérez, Pedro (2009), La rúbrica del poeta. La expresión de la autoconciencia poética de Boscán a Góngora, Valladolid, Universidad de Valladolid.

Ruiz Pérez, Pedro (2010), El Parnaso versificado. La construcción de la república de los poetas en los Siglos de Oro, Madrid, Abada. 
Ruiz Pérez, Pedro (ed.) (2018a), Sociología de la literatura hispánica: el autor y la institución literaria, monográfico de Studi Ispanici, XLIII.

Ruiz Pérez, Pedro (ed.) (2018b), «Diógenes Laercio y las biografías literarias en la edad moderna», en Tatiana Alvarado Teodorika, Theodora Grigoriadou y Fernando García Romero (eds.), Ecos y Resplandores Helenos en la Literatura Hispana. Siglos XVI-XXI, La Paz-Madrid, Sociedad Boliviana de Estudios Clásicos-Sociedad Española de Estudios Clásicos, pp. 605-627.

Ruiz Pérez, Pedro (ed.) (2019), Autor en construcción. Sujeto e institución literaria en la modernidad hispánica (s. XVI-XIX), Zaragoza, Prensas Universitarias de Zaragoza.

Ruiz Pérez, Pedro (ed.) (en prensa a), Representaciones de autor (XV-XIX). Retratos, biografías, polémicas, monográfico de Bulletin Hispanique, 121, 2.

Ruiz Pérez, Pedro (ed.) (en prensa b), «La polémica entre Sedano e Iriarte: punta y raíz de la espina», Philologia Hispalensis, 32, 2.

Ruiz Pérez, Pedro (ed.) (en prensa c), «Las biografías del Parnaso español: López de Sedano y el canon», en Homenaje a José Checa Beltrán.

Sánchez García, Encarnación (2013), «Libros ilustrados con retratos en la Nápoles española del primer Barroco», en Soledad Arredondo (ed.), Géneros híbridos y libros mixtos en el Siglo de Oro, monográfico de Mélanges de la Casa de Velázquez, 43. 2, pp. 95-117. $<$ C:IUsers\Usuario\Desktop\Libros ilustrados con retratos en la Nápoles española del primer Barroco.html>.

Sánchez Jiménez, Antonio y Adrián J. Sáez (eds.) (2018), Siete memoriales españoles en defensa del arte de la pintura, Madrid-Frankfurt, Iberoamericana-Vervuert.

Viala, Alain (1985), Naissance de l'écrivain: sociologie de la littérature à l'âge classique, Paris, Éditions du Minuit. 